\title{
Some geoecological aspects of suffosion danger in the road infrastructure using
}

\author{
Ivan Lavrusevich ${ }^{1, *}$, Alisa Podlesnykh ${ }^{1}$, Andrey Lavrusevich ${ }^{1}$ \\ ${ }^{1}$ Moscow State University of Civil Engineering, Yaroslavskoeshosse, 26, Moscow, 129337, Russia
}

\begin{abstract}
Danger of emergence and extension of suffosionprocessesis considered on the example of some objects of the road infrastructure. Need of the analysis and accounting of suffosionrisk in construction and operation of highways is proved. The model which is showing the mechanism of suffosion destruction of soils, hidden from direct observation in natural conditions, is given. The results of the experiment which is directed for the studying the features of extension of slope suffosion process near Schmidt Direction Street of Moscow are presented. The possibility of forecasting of emergence and extension of suffusion processes under the influence of natural and technogenic factors, and also determination of the amount of the expected underground and surface suffosionmanifestations (zones of destruction, cavities, failures, decreasing, etc.) is shown. Conclusions of the initiating reasons of suffosion processes on objects of road infrastructure and some preliminary recommendations for their prevention are made.
\end{abstract}

\section{Introduction}

Stable and effective functioning of road infrastructure is at a loss specific of hydro geological and climatic features of the territory. Studying and the accounting of features of emergence and extension of dangerous exogenous geodynamic processes is a necessary condition for the prediction of their further development and holding the actions weakening or excluding dangerous consequences $[1,2,3]$. In practice of industrial and civil engineering, and also at the subsequent operation of road infrastructure often underestimate a possibility of emergence and extension of the dangerous geological phenomenon called by «suffusion». According to the definition which was given in the Set of Rules, the suffosionrepresents destruction and carrying out by means of a stream of underground waters of separate components and large masses of the disperse and hardpan detrital breeds including composing structural elements of rocky arrays $[3,4]$. Despite the frequency of occurrence and variety of consequences, suffosion danger to objects of industrial and civil engineering is taken insufficiently seriously. On the one hand,thesuffosion is included in the list of natural influences, dangerous to construction, along with such processes as landslides, the karst and processing of coast of reservoirs, with another -it is considered only in a paragenesis with them and does not admit independent geological process $[5,6,7]$.

*Corresponding author:lavrusevichivan@mail.ru 
Power impact of a stream of underground waters on disperse breeds is result of a mechanical suffosion. Necessary conditions for extension of a mechanical suffosion are, first of all, the stream of underground water having a certain hydrodynamic force, area of carrying out of separate particles or large masses of the rock destroyed by a suffosion and also its structural and textural heterogeneity. The suffosion of technogenic character considerably dominates over natural and is dated for separate hydraulic engineering constructions, transport highways, objects of power and the industrial enterprises [2,8,9].

Emergence and extension of suffosion processes on objects of road infrastructure introduces a real danger as often leads to formation of failures, land subsidence and other dangerous exogenous geodynamic processes owing to which there is a deformation and destruction of their components (a roadbed, slopes, borders, systems of water disposal, etc.). Authors made an attempt of the description, analysis and forecast of extension o fsuffosion danger and risk at construction and operation of objects of road infrastructure[1,11]. Experimental natural modeling of extension of suffosionp rocesses is presented, and also some preliminary recommendations for their prevention are made.

\section{Results and discussion}

\subsection{Impact of slopesuffosion processes and a consequence of their extension on the monolithic concrete constructions, which applied to strengthening and protection of slopes of highways}

As an object of a research, the section of the highway near Schmidt Direction Street of the house $39 \mathrm{~A}, 6^{\text {th }}$ building of Moscow (Figure 1) served.

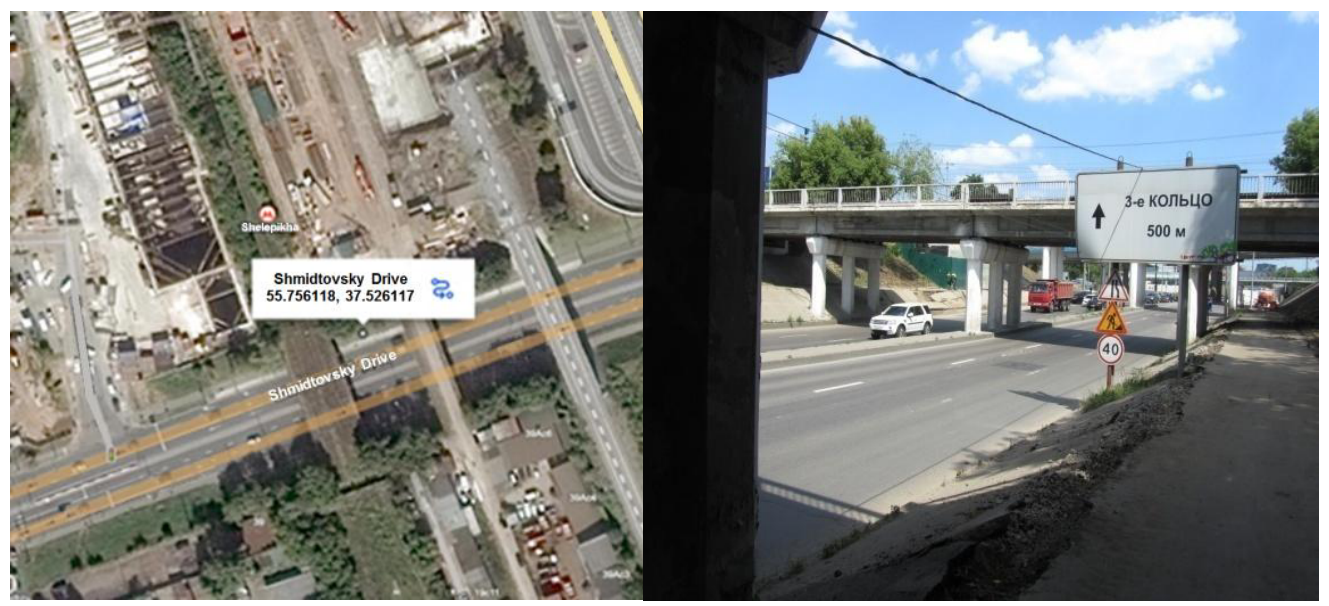

Fig. 1.The place of extension of suffosion and erosive processes on a highway slope near Schmidt Direction Street of the house 39 A, $6^{\text {th }}$ building of Moscow.

In the middle of June, 2016 authors revealed and recorded destruction and a failure of the plates of a covering of a slope which is adjoining to the lower reinforced concrete grillage dividing the strengthened slope and the carriageway of Schmidt Direction Street. (Figure 2). 


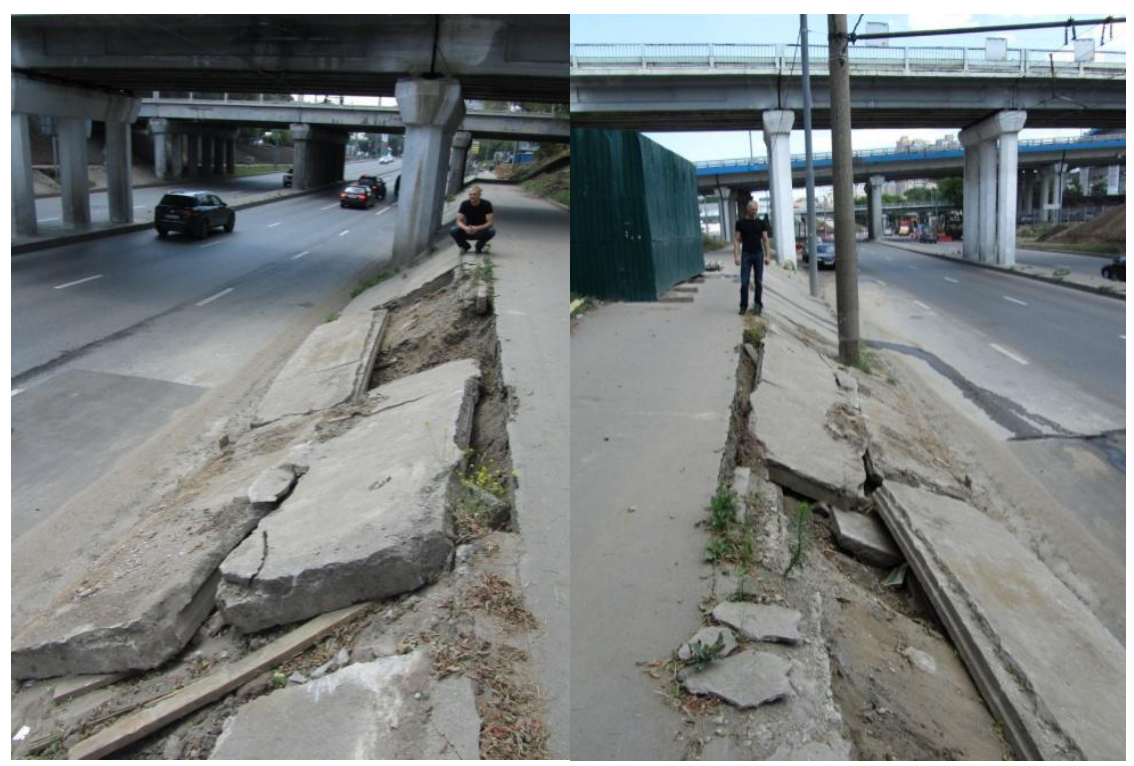

Fig. 2. Destruction of concrete plates of a slope of the highway near Schmidt Direction Street of the house $39 \mathrm{~A}, 6^{\text {th }}$ building of Moscow.

During a survey of the place of deformation of soil as a result of a suffosion, the destruction of concrete plates is visible, and above on a slope the initial stage of erosive washout of its surface (Figure 3 ) is found. As a result of an erosion of the soil horizon the root system of the trees and bushes growing on this slope is partially naked $[2,12]$.
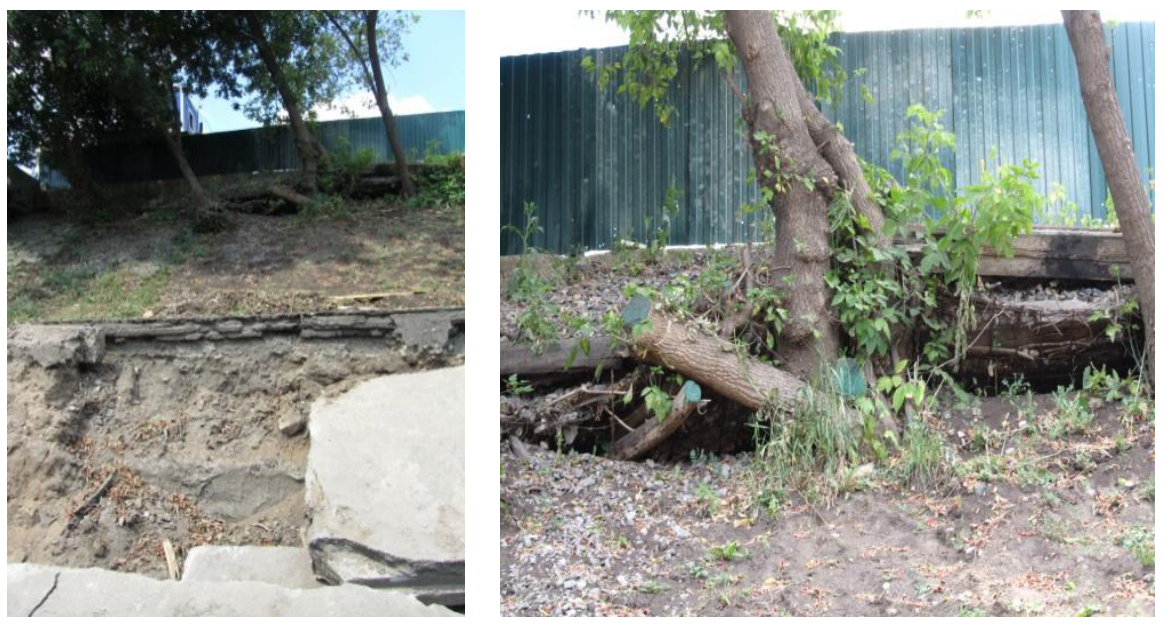

Fig. 3. Erosive destruction of a surface of a not strengthened slope and an exposure of root system of trees.

The basis of the slope strengthened by means of concrete plates is put largely and medium-grained sands with inclusion of a gruss and crushed stone that visually illustrates on the Figure 4. The approximate volume of the taken-out soil up $2.2 \mathrm{~m}^{3}$.

Intensive atmospheric precipitation, and uncivilized dumping of surplus of water from the building site which is above on a slope were the prerequisites which provoked a suffosion (Figure 4). The soils of a slope lost the structural durability. 


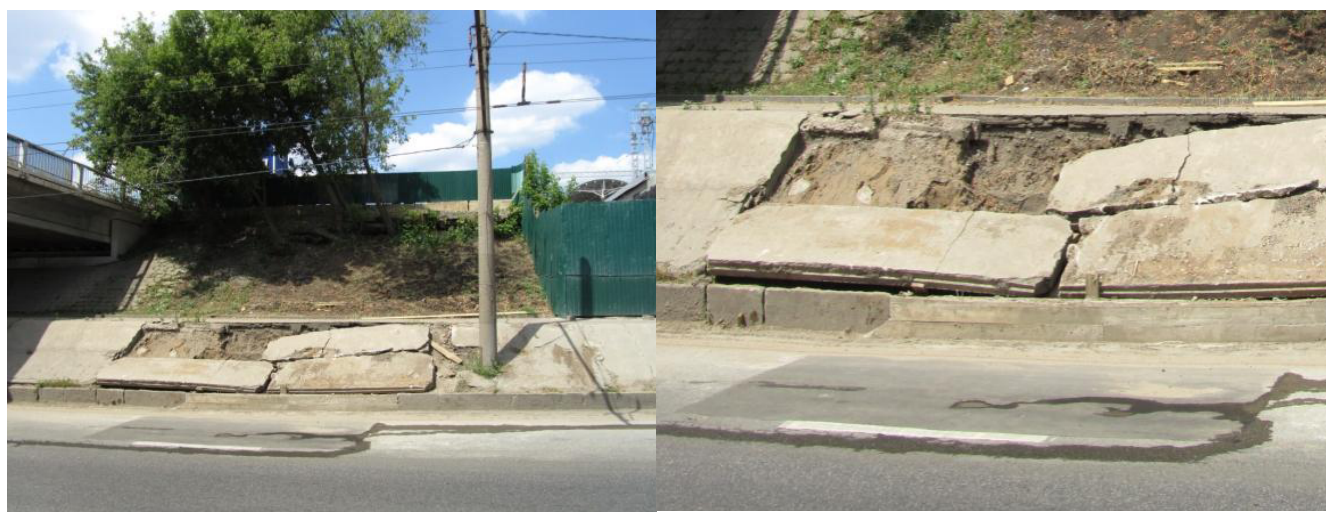

Fig. 4. The destroyed slope plates, the restored tape of a grillage, asphalt «patch».

The direction of carrying out of soil from top to down, under concrete plates of facing of a slope is visible. Extension of the suffosioncourse and the increased hydrodynamic pressure in the lower part of a slope caused carrying out of sandy soil, formation of a suffosion cavity and the subsequent to it a plate failure. During the further inspection of the place of destruction it was established that the reinforced concrete blocks dividing the strengthened slope and the carriageway were dismantled, and instead of them on this place the reinforced tape of a grillage is laid. Asphalt «patch» on the carriageway of the highway, is a consequence of extension of a suffosion. There was a subsidence and the subsequent failure of soil under asphalt covering that presumably initiated the shift and destruction of reinforced concrete blocks and plates of a slope.

At the beginning of October, 2016, (Figure 5) road services, made dismantle of concrete plates, partial recultivation of slopes and strengthening of the lower part of a slope by a gabion. However incorrectly organized system of a drain from the building site led to emergence and extension of erosive gullies on a slope surface again.
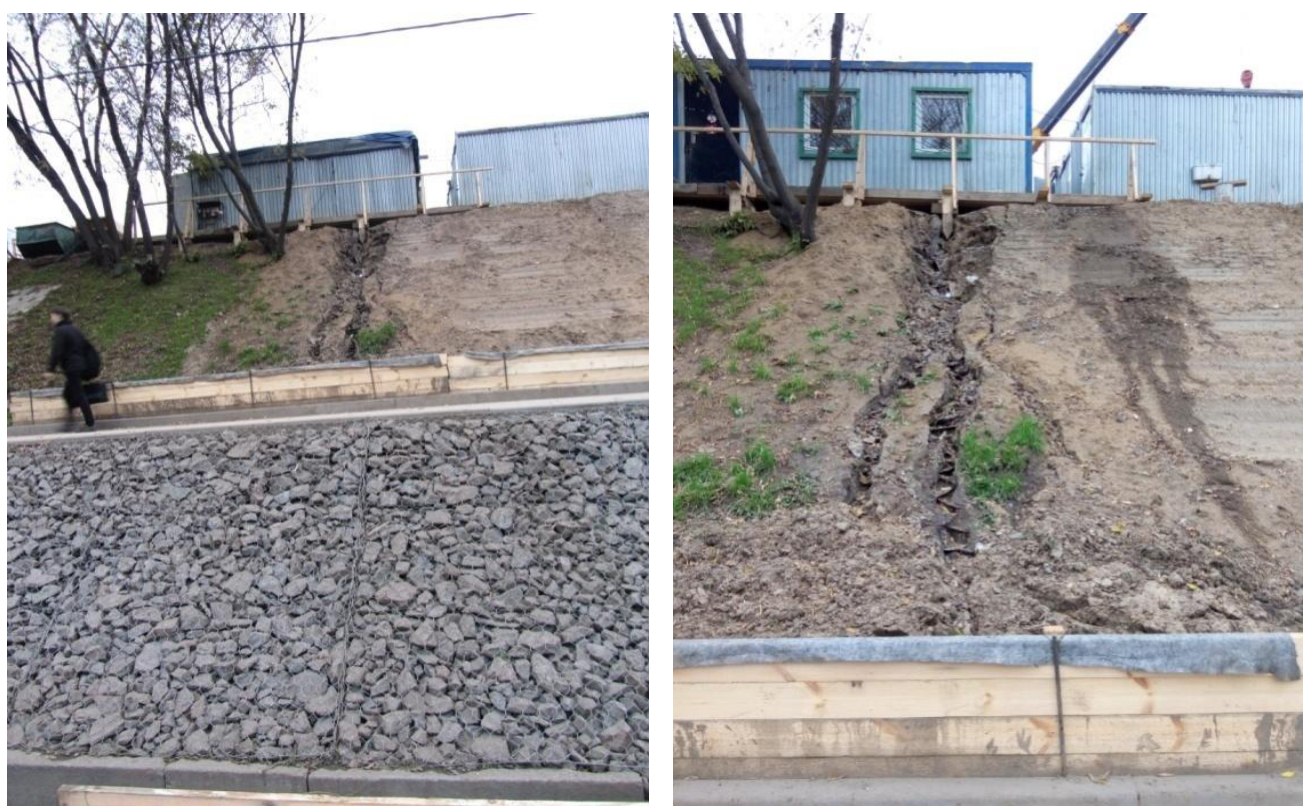

Fig. 5. The slope strengthened by a gabion. A large erosive gully on a slope surface. 
For studying of the mechanism of development of slopesuffosion process on a highway slope near Schmidt Direction Street of the house 39 A, $6^{\text {th }}$ building of Moscow, the authors were carried out its laboratory modeling. A technique of carrying out experiment. Installation for modeling of emergence and extension of suffusion processes represents the rectangular working camera manufactured of plexiglas with transparent walls.

The working camera having the sizes of $32 * 20 * 17 \mathrm{~cm} \mathrm{[2]} \mathrm{during} \mathrm{the} \mathrm{experiment} \mathrm{the}$ camera was filled with model material (initial soil) on height of $170 \mathrm{~mm}$, with coefficient of consolidation of $\mathrm{k}_{\text {com }} 0.9-0.88$ and under the inclination which was imitating a corner of a slope of the highway of the planned steepness - $33^{\circ}$. In continuous impenetrable bottom of foundation of installation was made the cut, which was imitating the suffosion channel. According to the experiment purpose atop obliquely of the located material of model the ceramic granite elements imitating the concrete plates strengthening a slope were laid. Material of model represented mix small, medium and coarse-grained sands with inclusion of a gruss and crushed stone. Working soil was selected and prepared so that the model, reflected structure of the original of material of the slope composing the basis as much as possible objectively. Particle size distribution of soil following: to $15 \%$ coarsely clastic, to $45 \%$ coarse-grained particles, and filler - particles less than $0.5 \mathrm{~mm}$ in size. Material of model has the texture imitating a natural object in which particles of filler have a possibility of free movement between soil skeleton particles under the influence of hydrodynamic forces, and thus, material of model is suffosion unstable. Then water supply, in a zone of its alleged penetration, under the bases of plates in the top point was organized. The sequence of stages of formation of a suffosion failure is shown on the Figure 6.
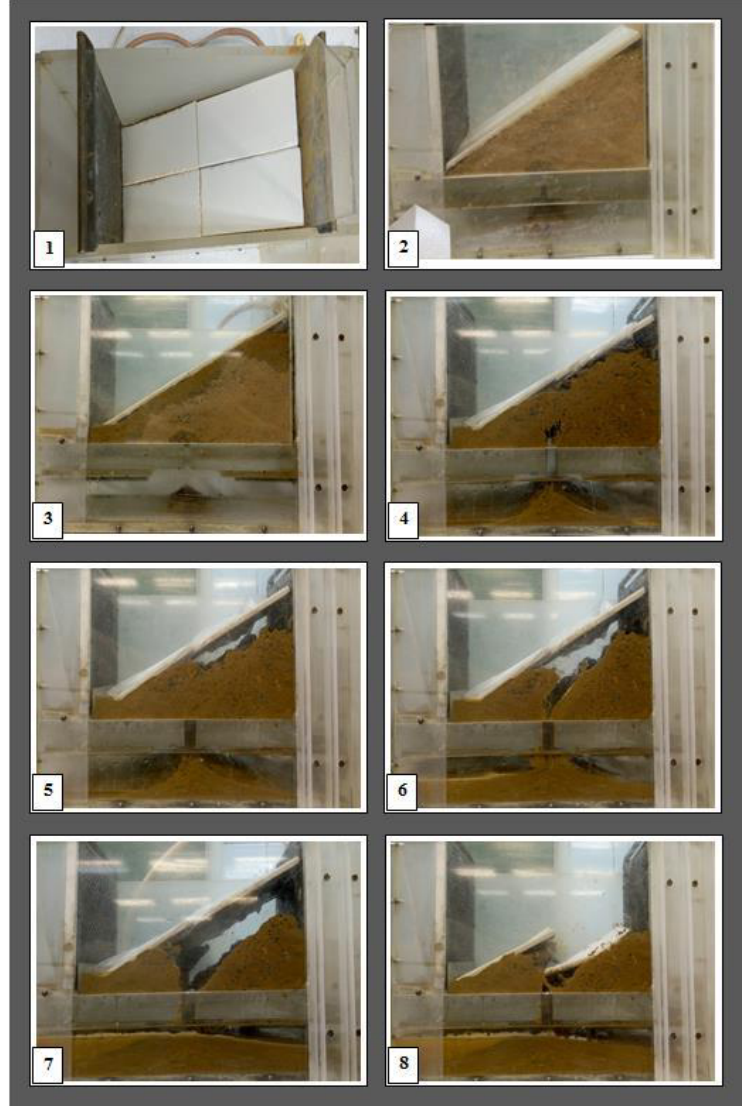

Fig. 6.Results of an experiment on imitation of formation of a suffosion failure on a highway slope. 
Thus, the hypothesis of the suffosion nature of the process which caused destruction and a failure of concrete plates of a slope of the highway near Schmidt Direction Street was confirmed.

Rejection of timely and effective measures for recultivation and strengthening of a slope, will lead to further aggravation of negative erosive process and considerable financial costs of its elimination. In a situation when at construction and operation of road infrastructure due attention is not paid to questions of strengthening and protection of slopes against washout and destruction, there are various, sometimes very serious and difficult removable problems.

\subsection{Impact of slope suffosion processes and a consequence of their extension on monolithic concrete constructions of system of water disposal from the carriageway of the highway}

As object of a research the site of a slope of the highway around crossing of OstashkovskoyeShosse highway and MRHW(Moscow ring highway)was used. (Figure 7). As system of water disposal on this section of the road serves the concrete tray (Figure 7) intended for dumping of surplus of water from the carriageway of the highway down to the slope basis.

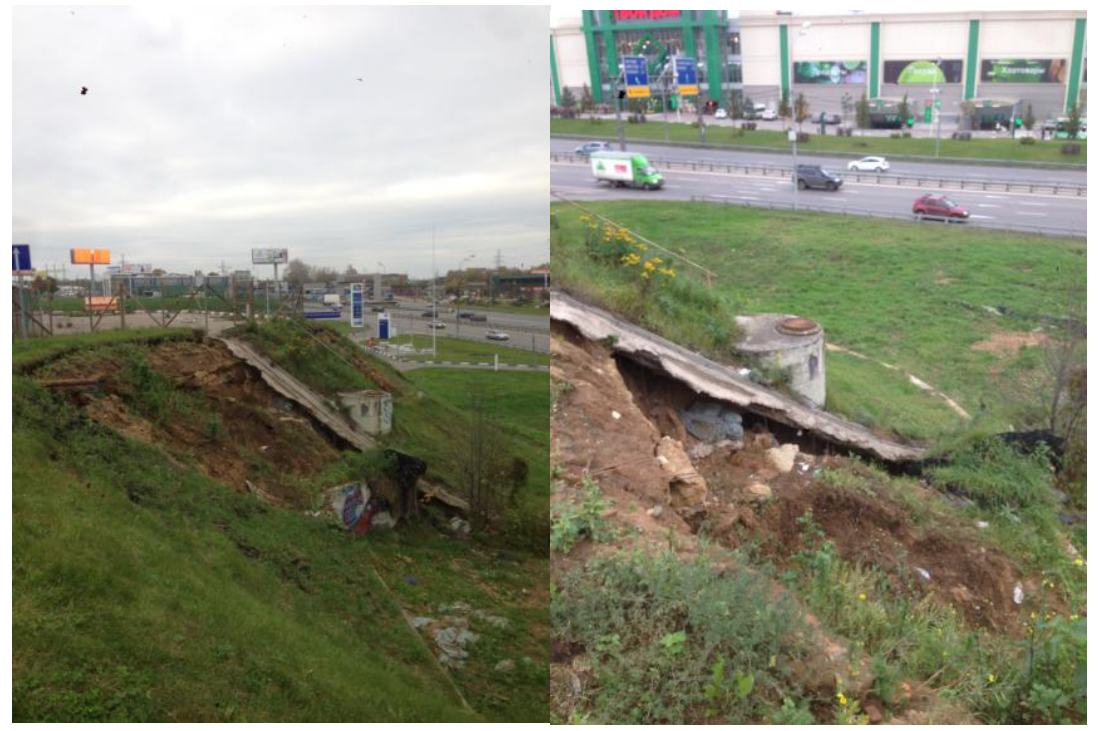

Fig. 7.The site of a slope of the highway around crossing of OstashkovskoyeShosse highway and MRHW.Reinforced concrete tray of system of water disposal.

However, because of a possible error of design and the wrong arrangement of a tray, water drainage on this site, actually, was not provided. Besides, during inspection of the adjacent territory, it was found, that there established a supplementalmetal pipe of water disposal (at the left, approximately in $17 \mathrm{~m}$ from a tray) (Figure 8). 


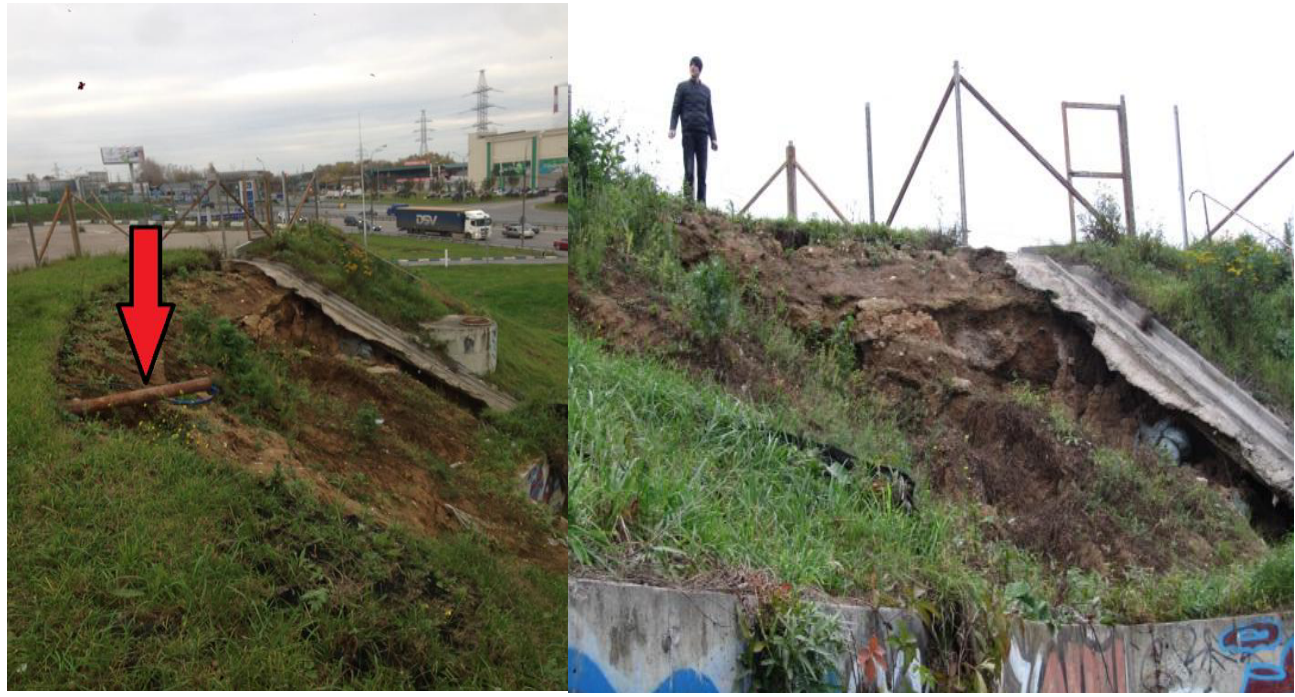

Fig. 8. Supplemental metal pipe of water disposal. A large erosive gully in the tray basis.

As a result of uncivilized dumping of water from the surface of the highway numerous erosive gullies on MRHWslope were created. And also, caused by suffosion processes, destruction of the basis of a tray of system of a drainage system (Figure 8). The approximate volume of the taken-out soil from under a reinforced concrete tray was 11.7 $\mathrm{m}^{3}$.

Not acceptance of a complex of the timely actions directed to elimination of consequences of suffosion-erosive destruction of a slope of the highway, and also the organization of civilized dumping surplus of water from the carriageway can also provoke extension of landslide process that will lead to failure of the site of MRHW.

\subsection{A failure in a pavement as result of development of suffusion process}

In June, 2015 on $24 \mathrm{~km}$, in the second row of inside ofMRHWthe failure by the size $3 \times 4.5 \mathrm{~m}$ and more than $2.5 \mathrm{~m}$ in depth was created. Asphalt "patch», on the place of a suffosion failure, demonstrates that shortly before this incident, in the same place the similar failure (Figure 9) was liquidated.

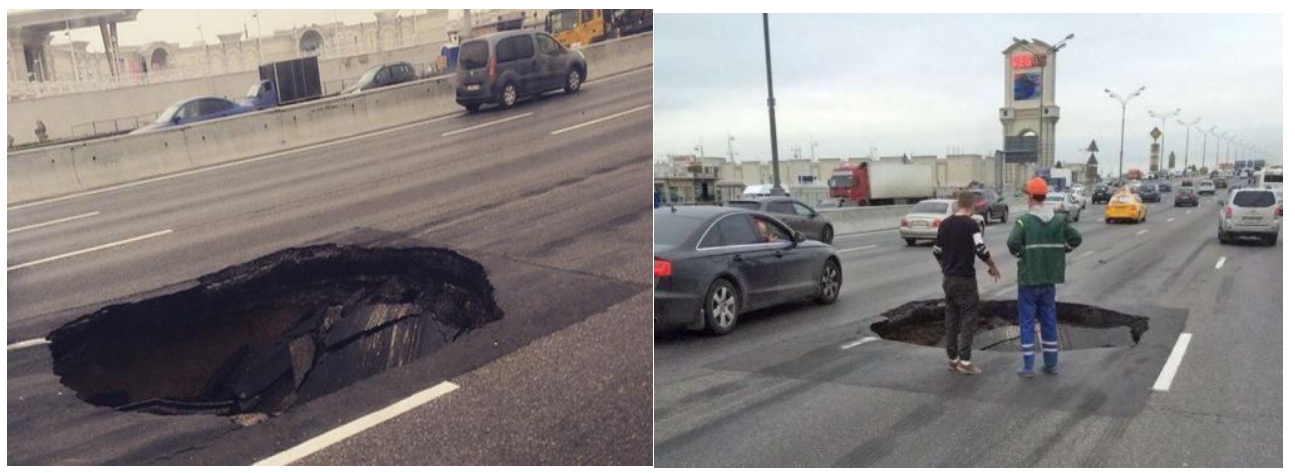

Fig. 9. A failure in the second row of inside of MRHW. Asphalt «patch» of the previous failure is visible. 
The numerous interviews given by various services, which arrived to the place of accident, came down to the fact that the failure happened because of the construction works connected with reconstruction of KashirskoyeShosse highway in this place. Duringthe studying of a situation, the authors established the true, whichcaused a failure. At first, emergence of a failure was preceded by plentiful rainfall that led to overflow of the existing collectors and impossibility of short-term dumping of the collected water (fig. 10). Increasing of a pressure head gradient in the place of an exit of a pipe of water disposal from regional shopping center to the highway of a drain in MRHWwas the second reason. The third, and the main reason of formation of a cavity under a roadbed, was low quality joining of pipes of the water highway (Fig. 11). During the increasing of the water level, at the expense of a pressure the water began to come to leaky interface of drainage reinforced concrete pipes and whirl took out sandy soil of the basis of an asphalt covering of the highway MRHW.
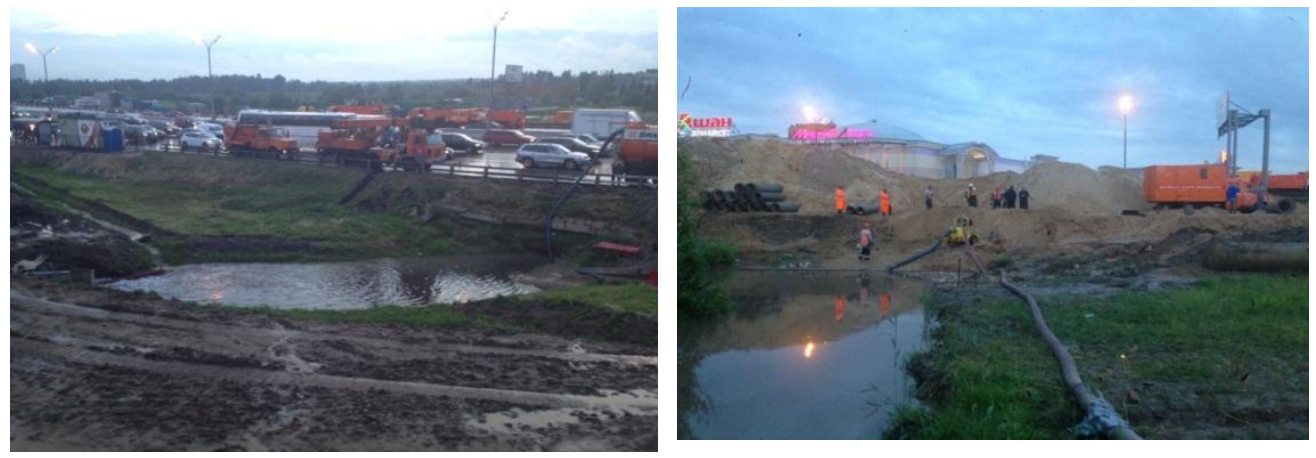

Fig. 10.Plentiful rainfall led to overflow of the existing collectors and increasing of head gradients pressure.
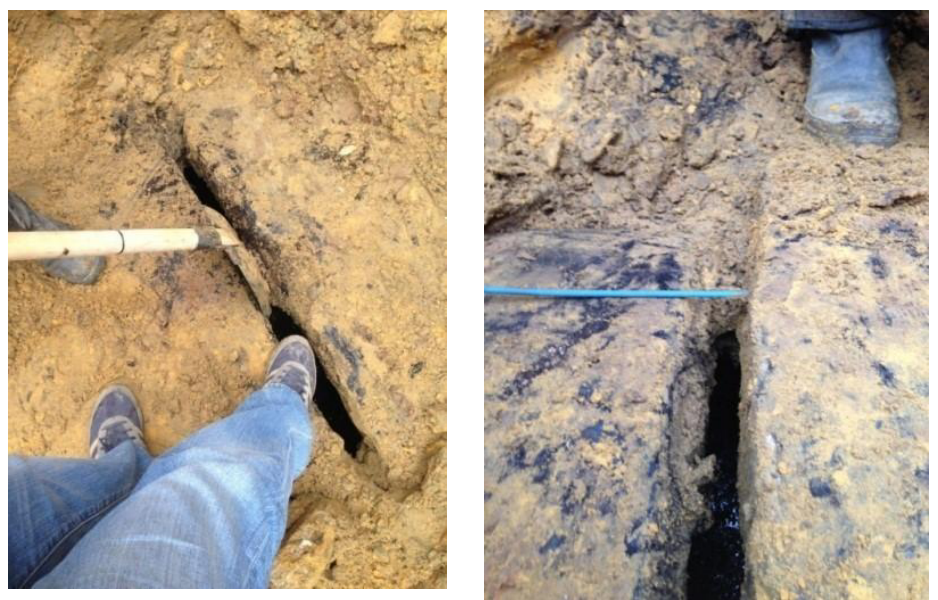

Fig. 11.Leaky joining of pipes of the water highway, width of an opening is $56 \mathrm{~mm}$.

\section{Conclusions}

1. At a research of numerous failures on the objects of road infrastructure and other urbanized territories it was established that in $92 \%$ of cases the lack of the centralized system of a drainage and water disposal was the cause of suffosion failures; the suffosionoftechnogenic character considerably dominates over natural. 
2. Underestimation of structural and textural features of the soil composing the bases of objects of road infrastructure at their construction and operation leads to emergence and extension of suffusion processes and constitutes real danger as often leads to formation of failures, land subsidence and other dangerous slope exogenous geodynamic processes owing to which there is a deformation and destruction of their components (a roadbed, slopes, borders, systems of water disposal, etc.), and also to serious financial costs.

Recommendations: Two versions of the solution of the appeared problem are possible: passive and active.

Passive events can be held after a development of a suffosion on a surface in the form of failures. The causes of a cavity are removed, it's filling with the condensed soil or concrete mix is made.

The active option represents the warning actions interfering of development of a suffosion. The careful waterproofing of interfaces of knots of designs and the organization of civilized system of a drainage and water disposal concerns to it.

\section{References}

1. J.A. Hudson, J.W. Cosgrove Int. J. Rock Mech. Min. Sci. 34, 577 (1997)

2. V.P. Khomenko Laws and predictions of the suffusion processes, 216 (2003)

3. Code of Rules 11-105-97, 93 (2000)

4. Code of Rules 116.13330, 60 (2012)

5. A.A. Lavrusevich, V.P. Khomenko, I.A. Lavrusevich, Proceedings of the Moscow State University of Civil Eng. 11, 54-57 (2015)

6. A.A. Lavrusevich, V.S. Krasheninnikov, I.A. Lavrusevich, Eng. Geol. 3, 48-58 (2012)

7. G.A. Kiersch, Eng. Geol. 45, 325-346 (1996)

8. A.I. Podlesnykh, I.A. Lavrusevich, Prospect and protection of mineral resources6, 4651 (2016)

9. M.R. Cave, O. Butler, J.M. Cook, M.S. Cresser, L.M. Garden, D.L Miles, Anal. At. Spectrom.15, 181-235 (2000)

10. R.N. Colvile, E.J. Hutchinson, J.S. Mindell, R.F. Warren, Atmos. Environ. 35, 15371565 (2001)

11. J.E. Lindqvist, U. Akesson, Bull. Eng. Geol. Environ. 60, 117-122 (2001)

12. F. Klijn, J.P.M.Witte, Hydrogeol. J. 7, 65 - 77 (2001) 